\title{
Hereditary Breast Ovarian Cancer Syndrome: One Case, Multiple Lessons
}

\author{
Juhaina Al Hinaii ${ }^{1}$, Moza Al Kalbani ${ }^{2}$, Marwa Al Riyami ${ }^{3}$, Abeer Al Sayegh ${ }^{4}$ and Ikram A Burney ${ }^{1 *}$ \\ ${ }^{1}$ Departments of Medicine, Sultan Qaboos University Hospital, Oman \\ ${ }^{2}$ Department of Obstetrics and Gynecology, Sultan Qaboos University Hospital, Oman \\ ${ }^{3}$ Department of Pathology, Sultan Qaboos University Hospital, Oman \\ ${ }^{4}$ Department of Genetics, Sultan Qaboos University Hospital, Oman
}

Submission: February 01, 2021; Published: February 11, 2021

*Corresponding author: Ikram A Burney, Departments of Medicine, Sultan Qaboos University Hospital, Oman

\begin{abstract}
Ovarian cancer is one the most common gynecological cancers, and epithelial ovarian cancer is the commonest sub-type. Between 10 and $15 \%$ of all epithelial ovarian cancers occur secondary to a mutation in BRCA1 or BRCA2 gene, and may be associated with breast cancer, known as hereditary breast ovarian cancer syndrome (HBOCS). We report a case of HBOCS, highlight the importance of family history and treatment history and discuss the recent developments in surgery and systemic treatment for patients in relation to the presentation of this case.
\end{abstract}

Abbreviations: HBOCS: Hereditary Breast Ovarian Cancer Syndrome; PARP: Poly ADP-ribose Polymerase; BER: Base Excision Repair

\section{Introduction}

Ovarian cancer is one the most common gynecological cancers [1]. Epithelial ovarian cancer is the commonest sub-type [2]. Between 10 and $15 \%$ of all ovarian cancers occur secondary to a mutation in a cancer susceptibility gene [3]. Mutations in BRCA1 and BRCA2 gene are the commonest cause of hereditary ovarian cancer $[4,5]$. These mutations also predispose the individuals to other cancers. Patients with epithelial ovarian cancer may also develop breast cancer [6,7]. We report one such case here, and discuss the recent advances in the medical and surgical management of hereditary breast ovarian cancer syndrome (HBOCS).

\section{Case Report}

A 57-year-old lady presented with abnormal vaginal bleeding and abdominal distention. She was diagnosed to have high grade ovarian cancer, underwent total abdominal hysterectomy, bilateral salpingo-oophorectomy and omentectomy, and was found to have stage IIIC serous papillary type of high grade ovarian cancer. The patient was treated with 6 cycles of Carboplatin and Paclitaxel to complete serological and radiological remission, however, she tolerated the chemotherapy with frequent episodes of febrile neutropenia. Three years later, the disease relapsed and the patient was treated with 6 cycles of Liposomal Doxorubicin to state of complete serological remission. One year later, the disease relapsed yet again, and this time, she received Carboplatin as a single agent. The disease entered serological remission after 3 cycles, however, the patient could not continue treatment because of repeated febrile neutropenia and thrombocytopenia

One year later, the disease relapsed a $3^{\text {rd }}$ time. CT scan showed disease only at one site (figure $1 \mathrm{a}$ ) and the patient was treated with Carboplatin at a reduced dose, once again to a state of complete serological and radiological remission (figure $1 \mathrm{~b}$ ). A surveillance mammogram was reported as BIRADS II and the bone mineral density revealed osteopenia. One year later, the disease relapsed a $4^{\text {th }}$ time, again in a solitary site, and the patient was counseled about treatment with chemotherapy followed by a secondary cyto-reductive surgery, to which the patient agreed. The patient received 6 cycles of chemotherapy at reduced doses, followed by surgery. There was no residual disease and the patient remained in complete remission for more than one year and 3 months.

At this stage the CA-125 was seen to rise again serially, and mammogram showed a $2.2 \mathrm{~cm}$ speculated lesion in the left breast. A fine needle aspiration was highly suggestive of breast cancer, 


\section{Journal of Gynecology and Women's Health}

and a core biopsy revealed an infiltrating ductal carcinoma, grade II, estrogen and progesterone receptor positive, but negative for HER-2/neu protein (ER positive; PR positive; HER-2/neu negative). The proliferation fraction measured by Ki-67 was $40 \%$. The morphologic and immunohistochemical patterns were consistent with a diagnosis of a primary in the breast (Table 1). Staging CT scan revealed a metastatic lesion in liver and bilateral pulmonary metastases. An attempt at guided biopsy from the pulmonary lesion was unsuccessful and led to pneumothorax. The patient refused further attempt at biopsy and agreed to be treated with Letrozole, considering that the pattern of metastases was more likely secondary to breast cancer rather than the ovarian cancer. Ten months later, the CT scan showed a marked regression in the size of pulmonary lesions, but a stable liver lesion (Figure 2).
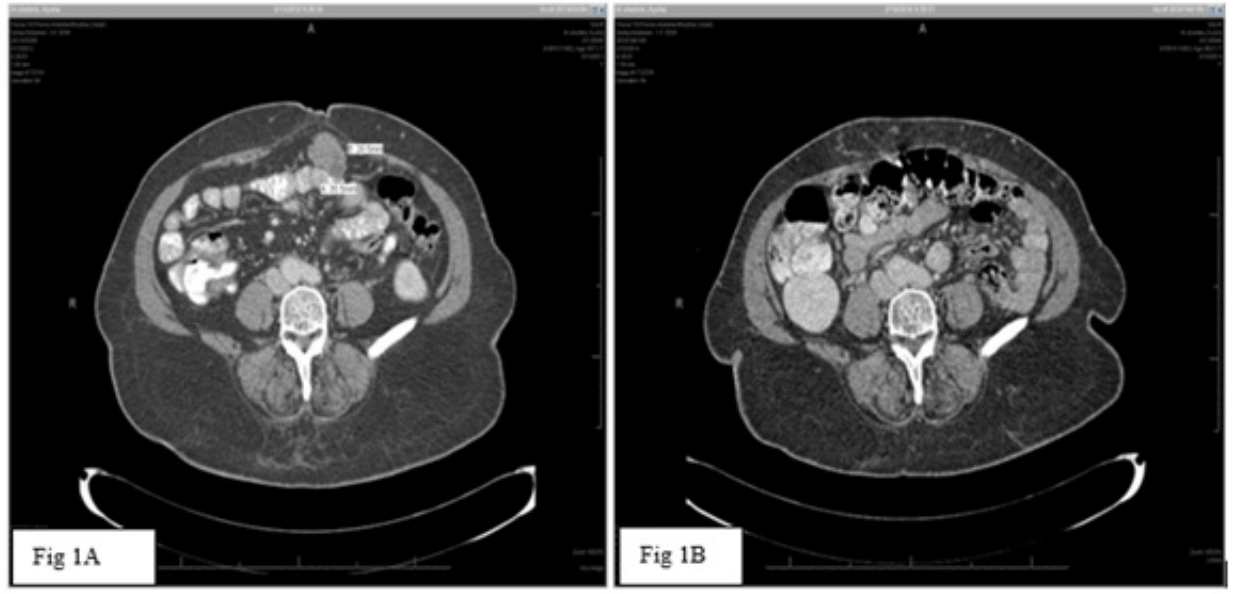

Figure 1: CT scan at the time of the 3rd relapse (Figure 1A) shows a $35 \mathrm{~mm} \times 28 \mathrm{~mm}$ mass in the region of omentum, which disappeared completely after 6 cycles of carboplatin AUC 4 (Figure 1B).

Table 1: Immunohistochemical staining patterns of breast and ovarian cancer. WT-1 (wilm's Tumor 1); PAX 8 (Paired box gene 8 ); CA 125 (Cancer antigen 125); ER/PgR (Estrogen receptor / Progesterone receptor); CK 7 (Cytokeratin 7); GCDFP-15 (Gross cystic disease fluid protein-15); TP 53 (Tumor protein 53).

\begin{tabular}{|c|c|c|}
\hline & Breast Cancer & Ovarian Cancer \\
\hline WT-1 & - & + \\
\hline PAX 8 & - & + \\
\hline CA 125 & - & + \\
\hline ER/PgR & + & + \\
\hline CK 7 & + & - \\
\hline GCDFP-15 & + & $+/-$ \\
\hline TP53 & + & + \\
\hline
\end{tabular}

Table 2: SCS: Secondary cyto-reductive surgery; CT: Chemotherapy; OS: Overall survival; HR: Hazard ratio; PFS: Progression-free survival.

\begin{tabular}{|c|c|c|c|c|c|c|}
\hline & \multicolumn{2}{|c|}{ GOG 213} & \multicolumn{2}{|c|}{ DESKTOP III/ENGOT-ov20 } & \multicolumn{2}{|c|}{ SOC1:SGOG-OV2 } \\
\hline & $\mathrm{SCS}+\mathrm{CT}$ & CT & $\mathrm{SCS}+\mathrm{CT}$ & CT & $\mathrm{SCS}+\mathrm{CT}$ & CT \\
\hline & 240 & 245 & 204 & 203 & 181 & 175 \\
\hline os & 50.6 & 64.7 & 53.6 & 46 & \multicolumn{2}{|c|}{ Not Reported yet } \\
\hline HR & \multicolumn{2}{|c|}{$1.29(0.97-1.72), p=0.08$} & \multicolumn{2}{|c|}{$0.75(0.58-0.96 ; P=0.02)$} & & \\
\hline PFS & 18.9 & 16.2 & 19.6 & 14 & 17.4 & 11.9 \\
\hline HR & \multicolumn{2}{|c|}{$0.82(0.66-1.01)$} & \multicolumn{2}{|c|}{$0.66(0.52-0.83), P<0.001$} & \multicolumn{2}{|c|}{$0.58(0.45-0.74) \mathrm{P}<.001)$} \\
\hline
\end{tabular}




\section{Journal of Gynecology and Women's Health}
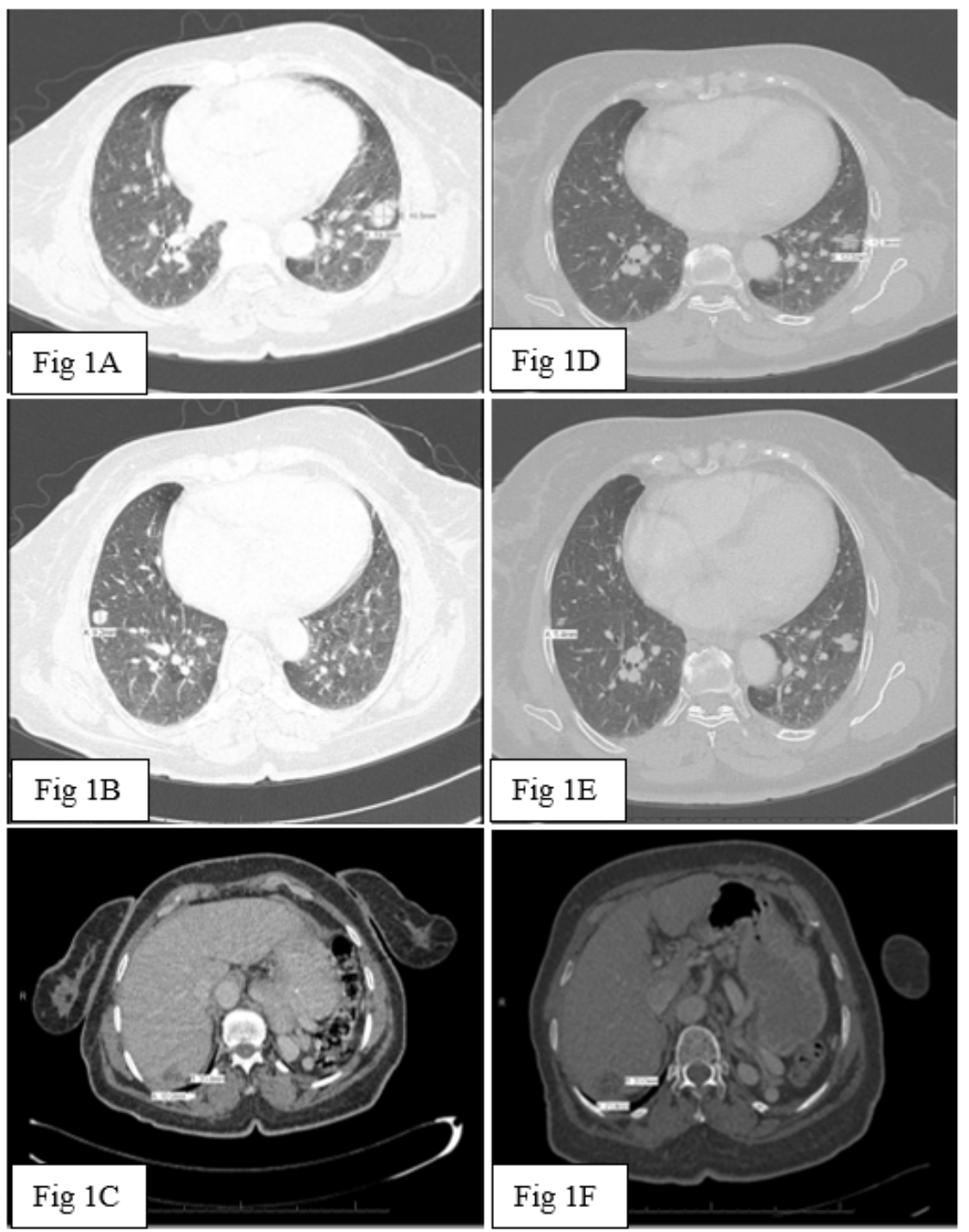

Figure 2: Staging CT scan at the time of the diagnosis of breast cancer. Figures $1 \mathrm{~A}, \mathrm{~B}$ and $\mathrm{C}$ metastatic lesions in left middle zone of lung, right middle zone of lung and the liver respectively, which regressed after 10 months of treatment with letrozole, as shown in figures 1D, E and $\mathrm{F}$ in the corresponding areas.

Considering that the patient had HBOCS, the patient was referred to the cancer geneticist. A detailed history revealed that her mother had dies of a malignancy of unknown primary site, her sister died at the age of 40 years, of a malignancy with ascites, but the primary site was not known to the patient or the family. The patient underwent counseling followed by assessment with a germline mutational analysis for breast and ovarian cancer panel, which revealed a pathogenic mutation in BRCA2 gene (c. $4243 \mathrm{G}>\mathrm{T}$ ), and a variant of unknown significance in the $N B N$ gene $($ c. $425 \mathrm{~A}>\mathrm{G})$. The BRCA2 mutation was consistent with a diagnosis of HBOCS. One year later, the CA 125 was seen to rise again serially, while the metastatic lesions in the lung and liver were under good remission. The patient was commenced on treatment with Olaparib, and the CA 125 dropped from 324 to 26 in one year (figure 3). The patient continued to receive Letrozole. Twelve years after the diagnosis of ovarian cancer, and while still on treatment for breast and ovarian cancer, the patient passed away of an unrelated cause. During the course of the treatment, patient's three daughters agreed for mutational analysis; two tested positive for mutation on the BRCA2 gene, and one of those two was screen-detected to have a breast cancer.

\section{Discussion}

We report the case of a woman diagnosed to have HBOCS, who lived 12 years after the diagnosis of high grade ovarian cancer, received multiple lines of intra-venous chemotherapy, albeit with difficulty, underwent a secondary cyto-reductive surgery, and in the last 4 years of her illness was treated for the two cancers with 
an oral aromatase inhibitor and a PARP inhibitor. Both breast and ovarian cancers responded to the treatment with the two oral agents. We would like to highlight several aspects of management for the general readership of this journal.

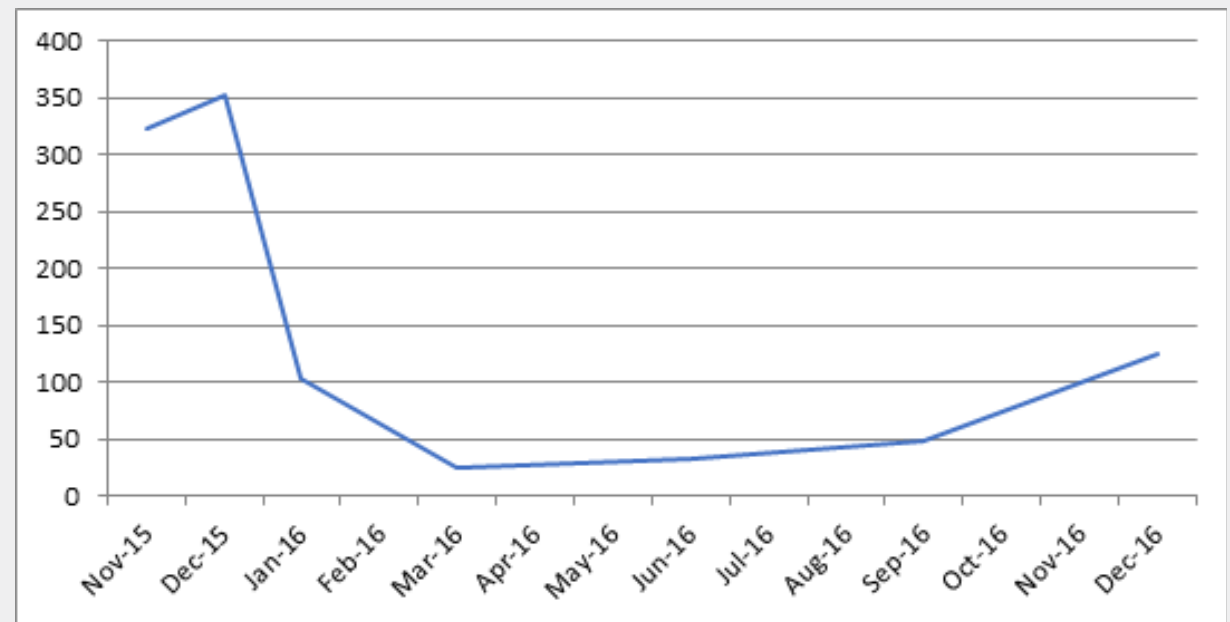

Figure 3: Serum CA 125 levels (IU/L) plotted over time. The patient was commenced on treatment with olaparib in Nov 2015. The levels dropped to within the normal limits (<36IU/L) in March 2016 (within 4 months of the treatment).

The median survival of patients diagnosed to have high grade ovarian cancer, stage IIIC is dismal at around 3-4 years [8]. This patient lived for 12 years. Complete response to chemotherapy on five occasions, and a poor tolerance to chemotherapy, even at an age of 57-65 years indicate the tumor is exquisitely sensitive, especially to platinum containing chemotherapy. Platinum derivatives (Cisplatin, Carboplatin and Oxaliplatin) are alkylating agents, which act by disrupting the DNA repair pathways. Usually, PARP (Poly (ADP-ribose) polymerase) enzyme is required for base excision repair (BER). If the enzyme were inhibited, DNA repair would be affected. Also, if one allele is inactivated on the BRCA 1 or 2 gene, such as, because of mutations or methylation, DNA repair will be grossly affected, leading to a process called 'synthetic lethality' $[9,10]$. In the last few years, three such compounds (Olaparib, Niraparib and Rucaparib) have been developed, tested, and have become the standard of care for patients with either germline BRCA mutations, or even in patients who may have homologous reconstitution deficiency [11-14]. The first-in-class compound was Olaparib, approved by the FDA in 2014 for use as a single agent in patients who had germline BRCA mutations and had failed three lines of chemotherapy [15]. Our patient was treated and responded to the treatment.

BRCA 1 mutation is more common than mutation in BRCA 2 gene, and it is important to distinguish between the two. Although, response to platinum chemotherapy or PARP inhibitors is the same [16], there are phenotypic differences, especially for breast cancer, and the susceptibility to develop other cancers, required for counseling the family members. Patients with $B R C A$ 1 mutation are associated with triple-negative breast cancer (ER negative; PR negative; HER-2/neu negative) in more than $75 \%$ of the cases, whereas, patients with BRCA 2 mutations are associated with hormone-receptor positive breast cancer in more than two thirds of the cases [17]. Our patient had BRCA 2 mutation and hormone-receptor positive breast cancer, which was treated with aromatase inhibitor for more than 4 years. Although the life-time risk of developing breast cancer is same (65-70\%) in the patients and the first-degree relatives, the life-time risk of ovarian cancer is $40-45 \%$ in case of BRCA 1 mutation carrier and $10-15 \%$ in case of BRCA 2 mutation career [18,19]. Our patient had three daughters and they were counseled. Two tested positive for the same mutation. Because of their relatively young age, and the minimal increased risk of ovarian cancer in BRCA 2 mutation carriers, till the age of 45 years, they were advised to consider delaying BSO.

The role of secondary cyto-reductive surgery in ovarian cancer has been contemplated and debated over the last several years. Three major phase III trials have been reported in the past 2 years (Please see table 2). The GOG-0213 trial was the first trial to have been reported [20]. The primary end point was overall survival (OS); 485 patients were randomized to receive standard of care chemotherapy with or without secondary cyto-reductive surgery. The patients were selected if the treatment free interval from the last dose of platinum containing chemotherapy was more than 6 months. Although, there was a non-significant prolongation in the progression-free survival (PFS) (18.9 vs 16.2 month; HR 0.82), there was no difference in OS. Actually, the OS was inferior in the group which received secondary cyto-reductive surgery (50.6 vs 64.7 months; HR 1.29). However, a sub-set of patients who achieved R0 resection had a better PFS and OS, compared to those who could not have a R0 resection. The DESKTOP III trial randomized 407 patients to receive standard of care chemotherapy with or without secondary cyto-reductive surgery (du Bois 2017). There was a clinically and statistically significant prolongation in the PFS 
(19.6 vs 14 months; HR 0.66). Also, the primary end-point was met [21]. The was a significant 7.6 months prolongation in OS (53.6 vs 46 months; 0.75 (0.58-0.96; $\mathrm{P}=0.02)$. In addition to the criteria of treatment free interval of more than 6 months, the investigators also used the AGO criteria. The AGO criteria was developed after the DESKTOP I trial, and women with no gross residual disease after primary surgery, ECOG performance status of $<1$, and no ascites on CT scan at recurrence were classified as AGO score positive [22]. Subsequently, the DESKTOP II trial suggested that patients with a good performance status, absence of ascites at the time for secondary cyto-reductive surgery, more than 12 months of platinum-free interval, isolated site of recurrence, and the possibility of complete resection of disease were likely to benefit from the secondary cyto-reductive surgery [21]. The $3^{\text {rd }}$ trial (SOC1 trial) randomly assigned 356 patients with recurrent ovarian cancer in first relapse to either chemotherapy, or cyto-reductive surgery and chemotherapy [23]. There was a clinically meaningful (5.5 months), and statistically significant prolongation in the PFS (17.4 vs 11.9 months; HR 0.58) for the combination of cytoreductive surgery and chemotherapy arm. The eligibility criterion was different from the first two studies. The SOC1 investigators selected patients if the platinum-free interval was at least 6 months, and an integrative model score was $<4.7$. However, at the time of management of our patient, results of the randomized trials were not available. We based our decision on the available data from DESKTOP I and II trials. The patient fit both the AGO score positive and the subsequent criterion developed after DESKTOP II trial. Our patient lived more than 5 years after the cyto-reductive surgery without a subsequent recurrence in the abdominal cavity.

Taken together, the three randomized trials comparing chemotherapy with or without cyto-reductive surgery suggest that there may be a benefit for surgery in carefully selected patients who can undergo potentially complete (RO) resection in women who have recurrent platinum-sensitive ovarian cancer. Although, results of randomized trials should not be compared, however, it would be useful to note that the magnitude of benefit seen in the DESKTOP III trial (HR 0.75), is similar to the recently reported SOLO2 study. The later study compared the OS in patients with platinum-sensitive ovarian cancer, but who also had a BRCA mutation, and who were treated with the PARP inhibitor, olaparib and had a median OS of 51.7 months compared to 38.8 months in the placebo arm with a HR of 0.74 [24]. Although, olparaib is the standard of care for maintenance treatment in patients with BRCA mutated platinum-sensitive ovarian cancer, the cost of drug and the overall cost of management remains very high. Cyto-reductive surgery in carefully selected patients, with a potential to achieve R0 resection may be an alternative, especially for patients with BRCA negative platinum sensitive ovarian cancer in first relapse.

\section{Conclusion}

we report the case of a patient with HBOCS, and highlight the recent developments in the systemic and surgical management of patients with ovarian cancer.

\section{References}

1. Bray F, Ferlay J, Soerjomataram I, Siegel RL, Torre l, et al. (2018) Global cancer statistics 2018: GLOBOCAN estimates of incidence and mortality worldwide for 36 cancers in 185 countries. CA Cancer J Clin 68: 394-424.

2. Kurman RJ, Carcangiu ML, Herrington CS, Young RH (2014) WHO classification of tumours of female reproductive organs. WHO Classification of Tumours. In: (4 $4^{\text {th }}$ edn), (6).

3. Zhang S, Royer R, Li S, McLaughlin JR, Rosen B, et al. (2011) Frequencies of BRCA1 and BRCA2 mutations among 1,342 unselected patients with invasive ovarian cancer Gynecol Oncol 121(2): 353-357.

4. Mikki Y, Swensen J, Shattuck-Eidens D, Futreal PA, Harshman S, et al. (1994) A strong candidate for the breast and ovarian cancer susceptibility gene BRCA1. Science 266(5182): 66-71.

5. Claus EB, Schildkraut JM, Thompson WD, Risch NJ (1996) The genetic attributable risk of breast and ovarian cancer. Cancer 77(11): 23182324.

6. Easton DF, Bishop DT, Ford D, Crockford GP (1993) The Breast Cancer Linkage Consortium. Genetic linkage analysis in familial breast and ovarian cancer: results from 214 families. Am J Hum Genet 52(4): 678701.

7. Easton DF, Steele L, Fields P, Ormiston W, Averill D, et al. (1997) Cancer risks in two large breast cancer families linked to BRCA2 on chromosome 13q12-13. Am J Hum Genet 61(1): 120-128.

8. Peres LC, Cushing-Haugen KL, Kobel M, Harris HR, Berchuck A, et al. (2019) Invasive epithelial ovarian cancer survival by histotype and disease stage. J Natal Cancer Inst 111(1): 60-68.

9. Helleday T (2011) The underlying mechanism for the PARP and BRCA synthetic lethality: clearing up the misunderstandings. Mol Oncol 5(4): 387-393.

10. Konstantinopoulos PA, Spentzos D, Karlan BY, Taniguchi T, Fountzilas E, et al. (2010) Gene expression profile of BRC Aness that correlates with responsiveness to chemotherapy and with outcome in patients with epithelial ovarian cancer. J Clin Oncol 28(22): 3555-3561.

11. Ledermann J, Harter P, Gourley C, Friedlander M, Vergote I, et al. (2014) Olaparib maintenance therapy in patients with platinum-sensitive relapsed serous ovarian cancer: a preplanned retrospective analysis of outcomes by BRCA status in a randomised phase 2 trial. Lancet Oncol 15(8): 852-861.

12. Mirza MR, Monk BJ, Herrstedt J, Oza AM, Mahner S, et al. (2016) Niraparib maintenance therapy in platinum-sensitive, recurrent ovarian cancer. N Engl J Med 375: 2154-2164.

13. Pujade-Lauraine E, Ledermann JA, Selle F, Gebski V, Penson RT, et al. (2017) Olaparib tablets as maintenance therapy in patients with platinum-sensitive, relapsed ovarian cancer and a BRCA1/2 mutation (SOLO2/ ENGOT-Ov21): a double-blind, randomised, placebocontrolled, phase 3 trial. Lancet Oncol 18(9): 1274-1284.

14. Coleman RL, Oza AM, Lorusso D, Aghajanian C, Oaknin A, et al. (2017) Rucaparib maintenance treatment for recurrent ovarian carcinoma after response to platinum therapy (ARIEL3): a randomised, doubleblind, placebo-controlled, phase 3 trial. Lancet 390(10106): 19491961.

15. Ledermann J, Harter P, Gourley C, Friedlander M, Vergote I, et al. (2012) Olaparib maintenance therapy in platinum-sensitive relapsed ovarian cancer. N Engl J Med 366: 1382-1392.

16. Antoniou A, Pharoah PD, Narod S, Risch HA, Eyfjord JE, et al. (2003) Average risks of breast and ovarian cancer associated with BRCA1 or BRCA2 mutations detected in case Series unselected for family history: a combined analysis of 22 studies. Am J Hum Genet 72(5): 1117-1130. 
17. Hartmann LC, Lindor NM (2016) The role of risk-reducing surgery in hereditary breast and ovarian cancer. N Engl J Med 374: 454-468.

18. Coleman RL, Spirtos Nm, Enserro D, Herzog TJ, Sabbatini P, et al.(2019) Secondary surgical cytoreduction for recurrent ovarian Cancer. Lancet 381:1929-1939.

19. Du Bois A, Vergote I, Ferron G, Reuss A, Meier W, et al. (2017) Randomized controlled phase III study evaluating the impact of secondary cytoreductive surgery in recurrent ovarian cancer. Journal of clinical oncology 35(Suppl 15): 5501.

20. Harter P, Du Bois A, Hahmann M, Hasenburg A, Burges A, et al (2006) Surgery in recurrent ovarian cancer: the Arbeitsgemeinschaft Gynaekologische Onkologie (AGO) DESKTOP OVAR trial. Ann surg oncol 13(12): 1702-1710.

21. Harter P, Sehouli J, Reuss A, Hasenburg A, Scambia G, et al. (2011)

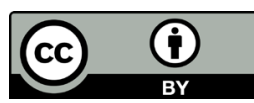

This work is licensed under Creative Commons Attribution 4.0 License

DOI: 10.19080/JGWH.2021.21.556052
Prospective validation study of a predictive score for operability of recurrent ovarian cancer: the multicenter intergroup study DESKTOP II. A project of the AGO Komission OVAR, AGO, study group, NOGGO, AGO-Austria, and MITO. Int J Gynecol Cancer 21(2): 289-295.

22. Du Bois A, Sehouli J, Vergote I (2020) Randomized phase III study to evaluate the impact of secondary cytoreductive surgery in recurrent ovarian cancer: final analysis of DESKTOP III/ENGOT-ov20. J Clin Oncol 38:15.

23. Zang R, Zhu J, Shi T (2020) A randomized phase III trial of secondary cytoreductive surgery in later recurrent ovarian cancer: SOC1:SGOGOV2. J Clin Oncol 38:15.

24. Poveda A, Floquet A, Ledermann JA (2020) Final overall survival (OS) results from SOLO2/ENGOT-ov21: A phase III trial assessing maintenance olaparib in patients (pts) with platinum-sensitive, relapsed ovarian cancer and a BRCA mutation. J Clin Oncol 38: 15.

\section{Your next submission with Juniper Publishers} will reach you the below assets

- Quality Editorial service

- Swift Peer Review

- Reprints availability

- E-prints Service

- Manuscript Podcast for convenient understanding

- Global attainment for your research

- Manuscript accessibility in different formats

( Pdf, E-pub, Full Tsext, Audio)

- Unceasing customer service

Track the below URL for one-step submission https://juniperpublishers.com/online-submission.php 